\title{
Flexible Strain-Tension Calculation Method for Gap-type Overhead Conductors
}

\author{
Igor Albizu, A. Javier Mazón, Member, IEEE, Inmaculada Zamora, Member, IEEE
}

\begin{abstract}
Commercially available sag-tension programs give good results for most practical applications. However, they have some limitations concerning gap-type conductors. A separate aluminum and core creep calculation is needed due to the especial structure of gap-type conductors. For the same reason, different core and aluminum lengths have to be considered. In order to take into account the creep during the installation process, flexibility for the consideration of several stages is needed. A method that considers all these characteristics has been developed and implemented in a comprehensive, versatile and flexible sag-tension software tool, called STOC (StrainTension in Overhead Conductors). The program has been designed for the analysis of gap-type conductors. However, the method is a general method that can be used for any type of conductor, especially when flexibility for the calculation of several creep conditions is needed.
\end{abstract}

Index Terms - creep, gap-type conductor, overhead conductor, sag-tension

\section{NOMENCLATURE}

$T$ tension

sag

length

area

elastic modulus

coefficient of thermal expansion

temperature

stress

total strain

strain related to temperature

strain related to tension

strain related to creep

strain related to metallurgical creep

strain related to geometrical settlement

time

$\theta^{\text {creep }}$ temperature increase that represents creep strain g related to catenary geometry

c related to conductor

core related to core

a related to aluminum

o related to reference condition

\section{INTRODUCTION}

S AG-TENSION calculation plays an important role in overhead lines design. On the one hand, tension of the conductor has to be high enough so that security distance to ground is maintained. On the other hand, wind, ice and everyday vibration conditions have to be considered so that the tension value is always below a certain security value. In addition, sag increase due to conductor creep has to be taken into account so that the above mentioned conditions are fulfilled during the line lifetime.

The final objective for engineers is to have a sagging table for the conductor installation. The sagging table is obtained taking into account the load and sag constraints. Engineers have good tools for a correct sag-tension calculation. The graphical method [1], developed in 1926, is widely used and gives a good level of accuracy. In a real installation, there are several uncertainties that affect the result and limit the accuracy needed in the calculation. For this reason, there are some methods that simplify the calculations. For example, the numerical sag-tension calculation method [2]-[4] does not model the creep effect but it represents it by a fixed temperature difference.

However, in certain cases, an accurate calculation makes sense. This is the case when uprating of an existing line is made by reconductoring with low sag conductors. In this case, it is important to know the ampacity increase so that the economical investment can be justified.

Low sag conductors are based on the conductor behavior above the knee-point temperature, where the aluminum is slack and only the core is under tension. This occurs due to the higher thermal expansion coefficient of the aluminum. Hence, above knee-point temperature the behavior of the conductor is based on the expansion coefficient of the core, which is lower than the expansion coefficient of the conductor. For this reason the sag increase with temperature is lower above knee-point temperature (Fig. 1).
I. Albizu is with the Electrical Engineering Department, Faculty of Engineering of Bilbao, University of the Basque Country, (e-mail: igor.albizu@ehu.es).

A. J. Mazón is with the Electrical Engineering Department, Faculty of Engineering of Bilbao, University of the Basque Country, (e-mail: javier.mazon@ehu.es).

I. Zamora is with the Electrical Engineering Department, Faculty of Engineering of Bilbao, University of the Basque Country, (e-mail: inmaculada.zamora@ehu.es). 


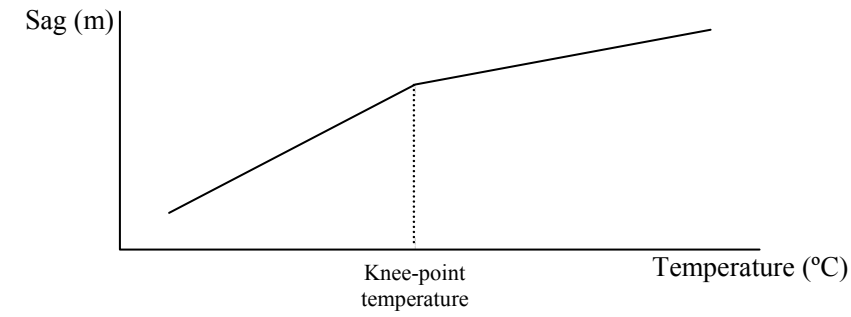

Fig. 1. Knee-point temperature.

In the case of gap-type conductors [5]-[7], the existing methods and software tools are not flexible enough. The structure (Fig. 2) and the installation process of gap-type conductors are special and they require a suitable calculation method. As it has been said, when a gap conductor is installed, the aluminum is slack and only the steel is under tension. Hence, a new method has been developed in order to overcome these drawbacks.
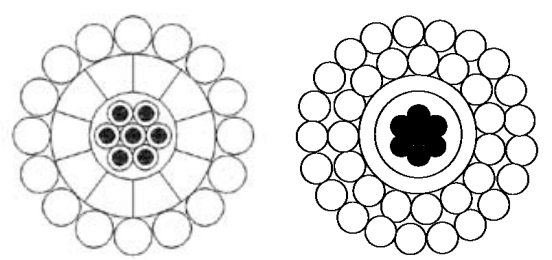

Fig. 2. Gap-type conductors.

\section{ASPECTS TO CONSIDER IN SAG-TENSION CALCULATION}

Sag-tension calculation is based on finding the tension $T$ and the length $L$ values that satisfy both span geometry and conductor behavior.

Conductor shape depends on weight and tension. The weight, in addition to the conductor weight, includes the effect of external loads due to wind or ice. Giving the horizontal length of the span $S$ and the height difference between connection points $h$, for certain load conditions, the conductor shape and hence its length and sag depend on tension value (Fig. 3).

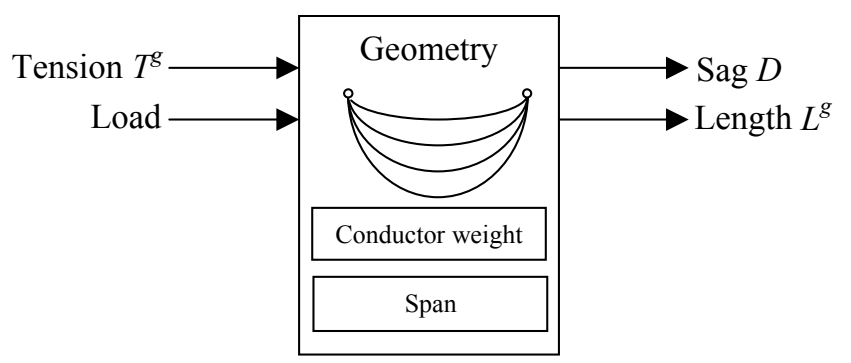

Fig. 3. Catenary length $L^{g}$ is a function of tension and load.

Giving the conductor length for certain temperature and tension, it changes as a function of both temperature and tension. In addition, the conductor experiences a permanent elongation due to creep. The creep effect is cumulative and depends on time, temperature and tension values. Besides, these length variations depend on conductor characteristics such as material types, area of each material, coefficient of thermal expansion, elastic modulus, etc (Fig. 4).

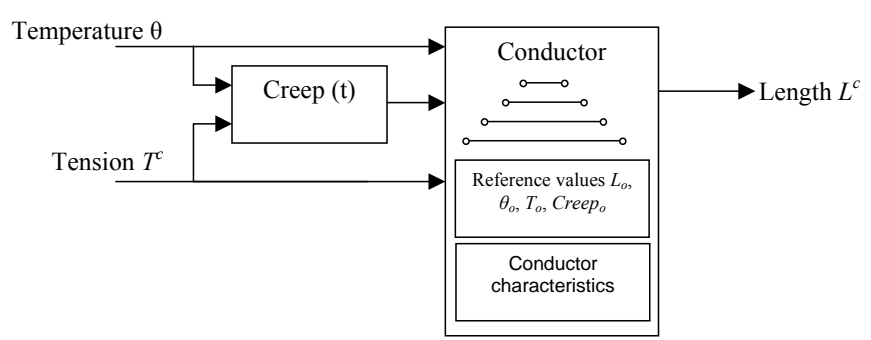

Fig. 4. Conductor length $L^{c}$ is a function of tension, temperature and creep.

There are infinite combinations for length and tension $L^{g}-T^{g}$ due to geometry. Their relation is determined by load. The higher the tension, the lower the conductor length (Fig. 5.a). In a similar way, there are infinite combinations for length and tension $L^{c}-T^{c}$ due to conductor behavior. Their relation is determined by temperature and creep. In this case, the higher the tension, the higher the conductor length (Fig. 5.b). Taking into account geometry and conductor constraints, there is only one $L-T$ combination that satisfies both constraints (Fig. 5.c). The objective of sag-tension calculation methods is to find out these tension and length values. Once these values are obtained, the sag is obtained from the geometry constrain.

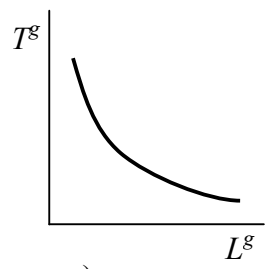

a)

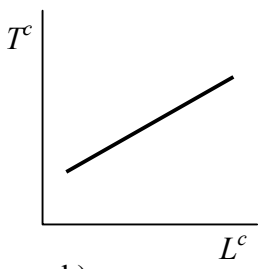

b)

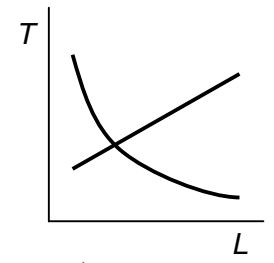

c)
Fig. 5. Tension-length a) Catenary geometry b) Conductor c) Combination of catenary geometry and conductor

The solution changes if any of the two $L-T$ curves changes. This occurs when load, temperature or creep change their value. The first step for sag-tension calculation is the definition of a reference condition. A reference tension value $T_{o}$ is defined for some reference load, temperature and creep values. From these values, the reference length $L_{o}$ can be calculated. Then, load, temperature or creep changes respect to the reference condition are considered to carry out the sagtension calculation. The solution is obtained by iterative procedures.

It is important to take into account the limitation of the sagtension calculation methods due to several uncertainties that affect the result. This issue is well addressed in [8]. Uncertainties related to conductor weight, end of span effects and flexibility of structures yield a sag calculation error of $1 \%$ to $2 \%$. Conductor weight usually exceeds the nominal value up to $0.6 \%$ and this value can be increased during conductor lifetime due to tarnishing effects or pollution. The modulus of elasticity is considered constant but actually it is a function of temperature. Similarly, the coefficient of thermal expansion, considered constant, is a function of the stress and the modulus of elasticity. Generally, these variations do not 
greatly affect the sag value. In case the conductor is at high temperature, other error sources are the radial thermal gradient of the conductor, the multiple span effects or the effect of manufacturing temperature.

\section{SAG-TENSION CALCULATION METHODS}

The graphic sag-tension calculation method [1], based on core and aluminum experimental curves, considers a detailed model of the conductor behavior. The strain summation method [9] also considers a detailed model of the conductor but it implements a different algorithm. Some methods, like the numerical method [2]-[4], consider a simplified model for the conductor. These methods are described in this section in order to be able to compare the differences between the new STOC method and the existing methods.

\section{A. Numerical method}

This method considers that both aluminum and core support tension, so it models the conductor as a whole. It calculates the conductor tension but it is not able to give the aluminum and core tension separately. A linear elastic behavior of the conductor is considered. The stress-strain relation is established by means of final elastic modulus. Conductor elastic modulus $E$ is obtained from core $E_{\text {core }}$ and aluminum $E_{a}$ elastic modulus and their respective areas, $A_{\text {core }}$ and $A_{a}$ (1). Conductor thermal expansion coefficient $\alpha$ is obtained from core and aluminum thermal expansion coefficients, elastic modulus and areas (2).

$$
\begin{aligned}
& E=\left(E_{a} \cdot A_{a}+E_{\text {core }} \cdot A_{\text {core }}\right) /\left(A_{a}+A_{\text {core }}\right) \\
& \alpha=\left(E_{a} \cdot A_{a} \cdot \alpha_{a}+E_{\text {core }} \cdot A_{\text {core }} \cdot \alpha_{\text {core }}\right) /\left(E_{a} A_{a}+E_{\text {core }} A_{\text {core }}\right)
\end{aligned}
$$

A reference condition must be defined and the rest of conditions are derived from it. Any condition can be defined as the reference condition. Reference length is obtained from span geometry and reference condition values (Fig. 6).

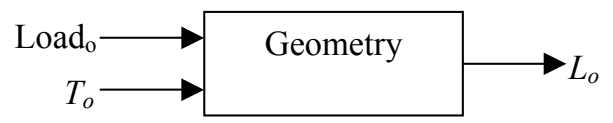

Fig. 6. Reference length $L_{o}$ for the numerical sag-tension calculation method.

The conditions can correspond to the initial state or to the final or creep state. Creep is represented by a temperature increase of the conductor $\theta^{\text {creep }}$. This temperature $\theta^{\text {creep }}$ is added to conductor real temperature to represent the elongation due to creep. This value is chosen based on calculations or utility field experience. For example, Spanish utilities consider $15^{\circ} \mathrm{C}$ for the creep in ACSR conductors.

Sag-tension calculation for other conditions different from the reference condition is carried out by an iterative process (Fig. 7). Conductor tension value $T$ is iterated until the difference between the length $L^{g}$ related to span geometry and the length $L^{c}$ related to conductor behavior is below a threshold value $(0.00001 \%$ of span length).

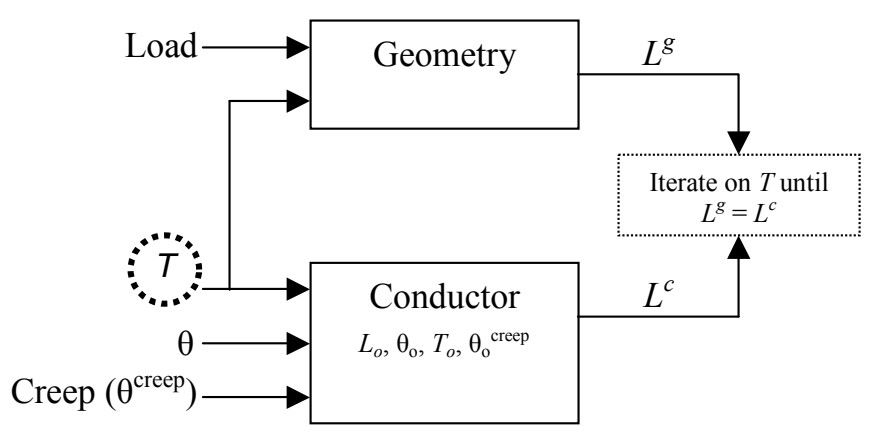

Fig. 7. Iterative process of numerical sag-tension calculation method.

As it does not calculate aluminum tension, this method is not able to model aluminum slack above knee-point temperature. For ACSR conductors this effect is not important. However, for other low-sag conductors such as gap-type conductors (Fig. 2) this effect is crucial.

\section{B. Graphical method}

Graphical sag-tension calculation method was developed in the twenties by Alcoa [1]. Conductor behavior is characterized by experimental stress-strain curves. In case of composite conductors, both core and aluminum curves are obtained. The method is implemented in commercial software programs such as Alcoa SAG10 and PLS-CADD. In order to represent the curves with the computer, these curves are given by equations that relate the virtual stress $\sigma^{\text {virtual }}$ and the strain $\varepsilon$ (3-5).

Initial curves represent the conductor after one hour creep. They are given by forth order polynomials (3). Creep curves are represented in a similar way (4). These curves represent the conductor after ten years creep. Final curves represent the conductor after the final creep. The final behavior is linear. The virtual stress and the strain are related by the final virtual elastic modulus $E^{\text {virtual }}(5)$. These curves are associated to the temperature $\theta_{\mathrm{o}}$ at which the tests have been carried out.

$$
\begin{aligned}
& \sigma_{\text {initial }}^{\text {virtual }}=a_{0}+a_{1} \cdot \varepsilon+a_{2} \cdot \varepsilon^{2}+a_{3} \cdot \varepsilon^{3}+a_{4} \cdot \varepsilon^{4} \\
& \sigma_{\text {creep }}^{\text {virtal }}=b_{0}+b_{1} \cdot \varepsilon+b_{2} \cdot \varepsilon^{2}+b_{3} \cdot \varepsilon^{3}+b_{4} \cdot \varepsilon^{4} \\
& \sigma_{\text {final }}^{\text {virtual }}=c_{0}+E^{\text {virtual }} \cdot \varepsilon
\end{aligned}
$$

Thermal expansion is considered by a displacement of the curves in the strain axis $\varepsilon$. This displacement is function of core and aluminum thermal expansion coefficients. At certain temperature $\theta$, the displacement for the aluminum and core curves are given by (6) and (7) respectively.

$$
\begin{aligned}
& \varepsilon_{a}^{\theta}=\alpha_{a} \cdot\left(\theta-\theta_{o}\right) \\
& \varepsilon_{\text {core }}^{\theta}=\alpha_{\text {core }} \cdot\left(\theta-\theta_{o}\right)
\end{aligned}
$$

Reference length $L_{o}$ is related to the conductor with no tension at stress-strain curves realization temperature, $\theta_{\mathrm{o}}$. It represents the conductor length before stringing and having any creep. It is obtained from span geometry, initial curves 
and an initial condition such as the installation condition (load, tension, temperature), as shown in Fig. 8.

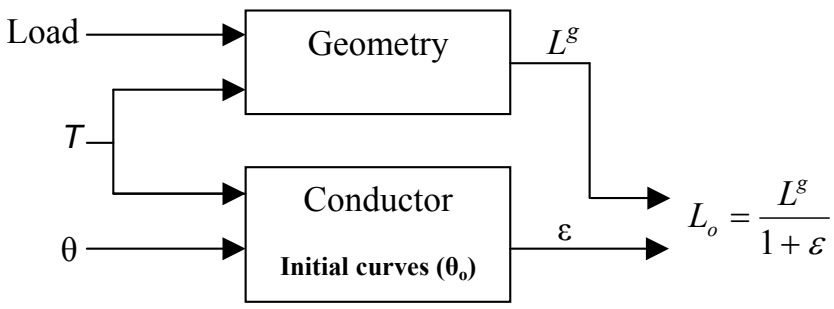

Fig. 8. Reference length $L_{o}$ for the graphical sag-tension calculation method.

The calculation is carried out by means of an iterative process (Fig. 9). A value of conductor length $L^{c}$ is considered and, taking into account the reference length $L_{o}$, the strain $\varepsilon$ is obtained. The stress-strain curves give the stress value $\sigma$ and conductor tension $T$ is calculated. With this value of $T$ the catenary length $L^{g}$ is obtained and compared with the considered conductor length $L^{c}$. Finally, conductor length is iterated until the difference is below a threshold value ( $0.00001 \%$ of span length).

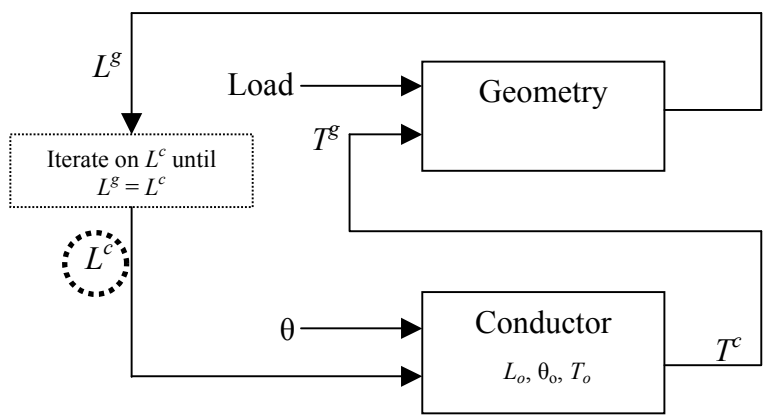

Fig. 9. Iterative process of graphical sag-tension calculation method.

The reference condition for final conditions is different because it is obtained taking into account the final creep. There are two options for final creep. The first option is to consider a continuous creep at a certain temperature, usually around $15^{\circ} \mathrm{C}$, during a certain period of time, usually 10 years (Fig 10.a). In this case, the final reference condition is obtained using creep curves in the iterative process. The second option is to consider an initial one hour creep associated to a maximum tension condition due to high load values (Fig. 10.b). In this case, the final reference condition matches the initial load condition. PLS-CADD shows both options in the final result whereas SAG10 chooses the option that gives a higher final sag.

Recently, an alternative algorithm process for calculation of final conditions has been proposed [4]. A parallel calculation of tension is carried out and the correct result is chosen between the two results obtained (Fig. 11). In one calculation process the conductor is modeled as a whole by the elastic modulus $E$ (1) and the thermal expansion coefficient $\alpha$ (2). In the other calculation process, it is supposed that the aluminum is slack and that only the core is in tension. In this case, the conductor is modeled by the core elastic modulus $E_{\text {core }}$ and the core thermal expansion coefficient $\alpha_{\text {core. }}$ The result that gives a higher tension and lower sag is chosen. The algorithm is different but the fundamentals are the same as in the graphical method. In order to simplify the calculation of tension due to geometry $T^{g}$, the authors use a parabolic model.
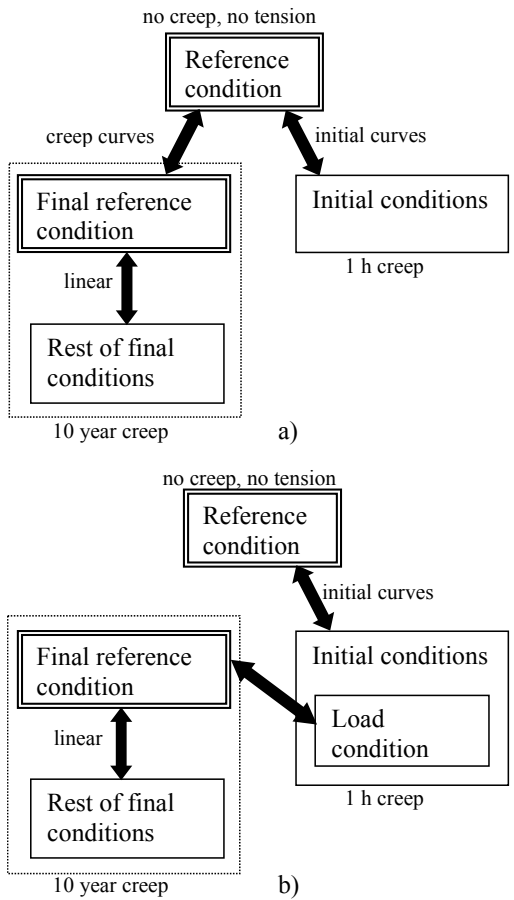

Fig. 10. Final reference condition a) Obtained from creep curves. b) Obtained from initial load condition

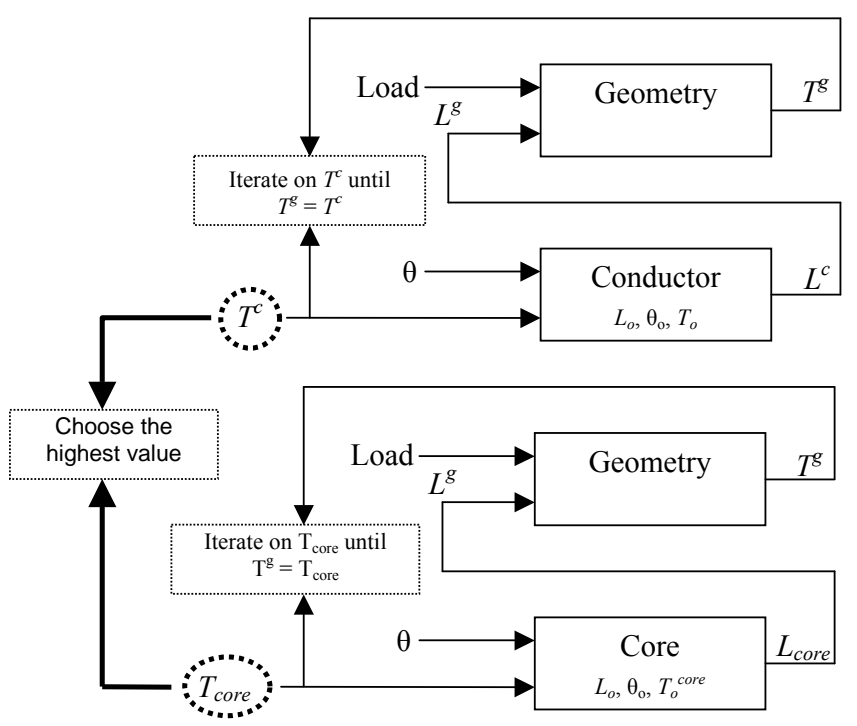

Fig. 11. Iterative process proposed in [7] for linear calculation of final conditions.

\section{Strain summation method}

This method [9] was proposed at the beginning of eighties as an alternative to the graphical method. The objective of this method is to give flexibility for the consideration of creep conditions. The method is characterized for having the 
conductor strain as the dependent variable. The strain can be caused by tension $\left(\varepsilon^{T}\right)$, temperature $\left(\varepsilon^{\theta}\right)$ and creep $\left(\varepsilon^{\text {creep }}\right)$. The creep is the result of the addition of metallurgic creep $\left(\varepsilon^{\mathrm{mc}}\right)$ and geometrical settlement $\left(\varepsilon^{\mathrm{gs}}\right)$. Each of these strains is evaluated individually and they are added to obtain the total strain. This process is carried out for the aluminum and the core separately, (8) and (9).

$$
\begin{aligned}
& \varepsilon_{a}=\varepsilon_{a}^{T}+\varepsilon_{a}^{\theta}+\varepsilon_{a}^{g s}+\varepsilon_{a}^{m c} \\
& \varepsilon_{\text {core }}=\varepsilon_{\text {core }}^{T}+\varepsilon_{\text {core }}^{\theta}+\varepsilon_{\text {core }}^{g s}+\varepsilon_{\text {core }}^{m c}
\end{aligned}
$$

The iterative process is shown in Fig. 12. As the strain is defined as dependent variable, both core and aluminum tensions are unknown. In order to have only one unknown variable for the iteration, the aluminum tension $T_{a}$ is obtained as the difference between the conductor tension $T^{g}$ obtained from the geometry constraint and the core tension $T_{\text {core }}$ that is the independent variable of the iteration.

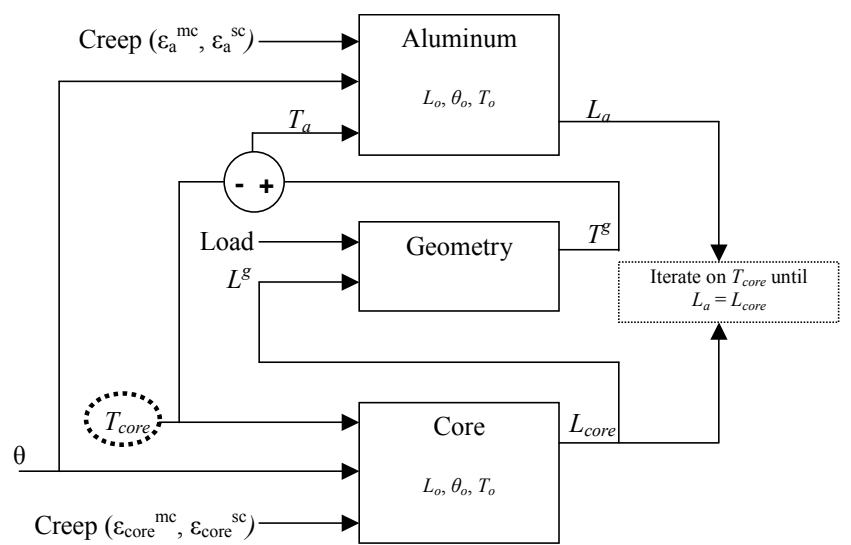

Fig. 12. Iterative process of strain summation sag-tension calculation method.

The authors developed a theory with respect to the transition process where the aluminum gets slack. They determined that before the aluminum gets slack, it experiences a compression that is around 10 and $15 \mathrm{MPa}$ for most conductors [10]. Hence, due to this effect, the knee-point temperature where the aluminum gets slack is increased. Currently, the graphical method implemented in SAG10 and PLS-CADD also considers this effect.

\section{STOC, A FLEXIBLE GAP-TYPE OVERHEAD CONDUCTOR STRAIN-TENSION CALCULATOR}

\section{A. Requirements and main characteristics}

A sag-tension calculation method suitable for gap-type conductors is required. The requirements for the sag-tension calculation are the following:

- Independent core and aluminum creep calculation. In the case of ACSR conductors it is usual to test and calculate the creep for the whole conductor. Although steel and aluminum have different behavior, for a certain type of conductor, with a certain steel and aluminum area, conductor creep can be predicted from conductor test results. For a given conductor tension, the steel and aluminum initial tension distribution and the change of the tension distribution pattern with time is the same for all ACSR conductors of a certain type. The case of gap-type conductors is different. For a certain type of gap-type conductor, with a certain steel and aluminum area, for a given conductor tension, the steel and aluminum relative tension distribution depends on the installation tension, which is applied only to the core. For this reason, the conductor creep test is not enough for gap-type conductors and a separate consideration of core and aluminum creep has to be carried out.

- Different core and aluminum total strains. When a gap conductor is installed, both core and aluminum have the same length but only the steel is under tension. Hence, with no tension, the steel length is lower than the aluminum length. The relative length between the steel and the aluminum, when they are with no tension, depend on the span length and the installation tension applied to the core. Hence, although aluminum and core have the same length, their total strain values are different. This occurs only in gap-type conductors.

- Calculation of creep for the installation process. The installation process is special and comprises several steps. For a few minutes, around $70 \%$ of sagging tension is applied only to the aluminum. In the final installation step, the whole sagging tension is applied only to the steel for a few hours, between 2 and 24 hours depending on the span. A correct creep evaluation is desirable as the creep developed during the installation process will reduce the final creep. This is because elongation due to creep develops more rapidly at the first moments and its rate decreases with time. Hence, it is said that creep that occurs during installation is removed from the final creep.

In order to fulfill these requirements, a new sag-tension calculation method has been developed. This method has been implemented in a software tool, called STOC. The main characteristics of the method are the following:

- Creep calculation procedure based in the CIGRE proposal [11] is used. The strain due to creep is calculated for both core and aluminum.

- There is only one reference condition for the calculation. This reference condition is the conductor with no tension and no creep at manufacturing temperature.

- Different reference lengths for core and aluminum are considered. In order to take into account the aluminum and core strain differences there are two options. One option is to calculate the actual lengths at no tension and take them as the reference lengths for core and aluminum. In this case, the total strain values for core and aluminum are different. Another option is to consider the same reference length for both core and aluminum. In this case, as the total strain has to be the same for both core and aluminum, a constant fictitious strain that considers the relative length difference has to be added to the aluminum. The first 
option has been chosen because it is more realistic.

- A sag-tension calculation method based in the strain summation method is used. The algorithm has been adapted, though. This method is appropriate for the above mentioned creep calculation method. Furthermore, it allows the analysis of several creep stages and the consideration of different reference lengths for core and aluminum as required.

- Aluminum compression can be considered if required. The calculation algorithm takes into account the compression before the aluminum gets slack.

Fig. 13 shows a schematic diagram of STOC. All conditions are calculated from the reference condition. The first stage corresponds to the installation process where all the installation steps are considered. Then, several creep stages can be considered. Creep is calculated sequentially and temperature and load variation are considered inside every creep stage. The strain due to creep is cumulative and depends on the previous creep stages.

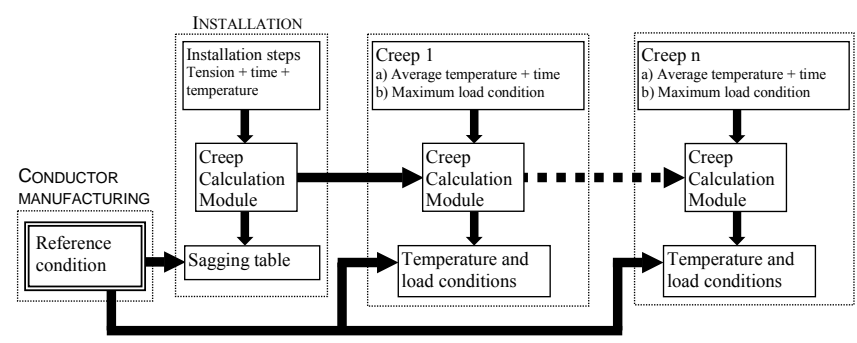

Fig. 13. Schematic diagram of STOC.

\section{B. Reference lengths}

The reference lengths corresponding to the reference condition with no tension and no creep are obtained from a condition where all strain values are known for both core and aluminum. This condition is the installation condition, where temperature and tension are known and creep strain can be estimated from the installation process. Independent core and aluminum reference lengths are considered (Fig. 14).

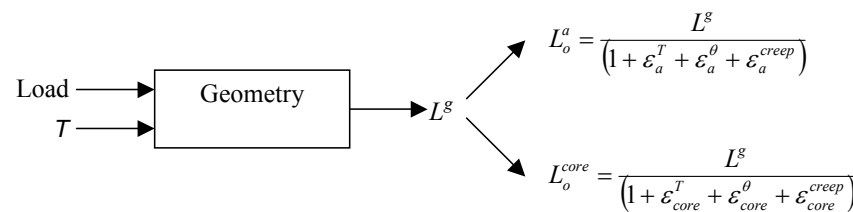

Fig. 14. Reference lengths $L_{o}{ }^{a}$ and $L_{o}{ }^{c o r e}$ for the STOC sag-tension calculation method.

If the method was applied to conventional conductors such as ACSR conductors, the reference lengths for core and aluminum would have the same value.

\section{Mechanical behavior}

An elastic linear mechanical behavior is supposed. The relation between tension and strain is determined by the final elastic modulus of aluminum and core, (10) and (11).
$\varepsilon_{a}^{T}=T_{a} /\left(E_{a} A_{a}\right)$
$\varepsilon_{\text {core }}^{T}=T_{\text {core }} /\left(E_{\text {core }} A_{\text {core }}\right)$

\section{Thermal behavior}

Strain due to thermal expansion is characterized by the coefficient of thermal expansion of the aluminum and core (6) and (7). The reference temperature corresponds to the manufacturing temperature because it is the temperature at which if core and aluminum had freedom of movement they would have the same length. At any other temperature the lengths are not the same and internal stresses appear in conductors such as ACSR. If the manufacturing temperature is unknown, a value of $15{ }^{\circ} \mathrm{C}$ is chosen as the manufacturing temperature is expected to be around this value.

\section{E. Creep}

Aluminum and core creep are calculated independently. In both cases, total creep $\varepsilon^{\text {creep }}$ is calculated as the addition of the metallurgical creep $\varepsilon^{\mathrm{mc}}$ and the strain due to geometrical settlement $\varepsilon^{\mathrm{gs}}(12)$. The strain due to geometrical settlement is supposed to be independent of time. It is only dependent on the conductor construction and the maximum tension experienced by the conductor. The metallurgical creep depends on stress $\sigma$, temperature $\theta$ and time $t$. The higher these values are, the higher the metallurgical creep is. As given in [11], the metallurgical creep in conductor wires follows the law given in (13), where $K, \Phi, \beta$ and $\mu$ are constant coefficients. These coefficients are derived from experimental tests. For constant temperature and stress values, metallurgical creep is a function of time (14), where $m$ is a constant value that is function of stress $\sigma$ and temperature $\theta$ (13). If both metallurgical creep and time are expressed in a logarithmic axis, a linear relation is obtained (15). This relation permits to extrapolate creep test results to longer periods of time.

$$
\begin{aligned}
& \varepsilon^{\text {creep }}=\varepsilon^{m c}+\varepsilon^{g s} \\
& \varepsilon^{m c}=K \cdot e^{\Phi \theta} \cdot \sigma^{\beta} \cdot t^{\mu} \\
& \varepsilon^{m c}=m \cdot t^{\mu} \\
& \log \left(\varepsilon^{m c}\right)=\log (m)+\mu \cdot \log (t)
\end{aligned}
$$

The metallurgical creep rate depends on time as it is shown in (13-15). The creep rate is highest at the beginning and it decreases with time. However, when the stress and temperature conditions change, the creep rate changes and it has been shown that its value is not dependent on the total time the conductor has been under stress but on the total strain developed. An equivalent value of time $t_{e}$ has to be calculated. This equivalent value represents the period of time in which the total strain developed by metallurgic creep would have been developed with the new conditions. If the new conditions are higher than the previous ones, the equivalent time decreases. If the new conditions are lower than the previous ones, the equivalent time increases. If the equivalent time is higher than the total time the wires have been under stress, the wires do not develop any strain until the total time under 
stress gets higher than the equivalent time.

In order to make the calculation of creep, time is divided in several periods where stress and temperature values are considered to be constant. If the period of time is long, the stress decreases as the creep strain increases. In this case, the period of time is divided in short sub-periods in which the change in stress and creep strain is small enough. In [11], subperiods in which the change in strain are around $20 \mu \mathrm{m} / \mathrm{m}$ are considered.

The first step is the calculation of the equivalent time $t_{e}$ associated to the temperature $\theta_{\Delta}$ and the stress $\sigma_{\Delta}$ of the period or sub-period $\Delta \mathrm{t}$ (16). The temperature value is known and the stress has to be calculated as a function of span characteristics, load, temperature and creep developed so far. In STOC, the stress is calculated by using the algorithm described below (Fig. 15).

$t_{e}=\left[\varepsilon_{o}^{m c} /\left(K \cdot e^{\phi \theta_{\Delta}} \cdot \sigma_{\Delta}^{\beta}\right)\right]^{(1 / \mu)}$

The second step is the calculation of the metallurgical creep developed in the period or sub-period $\Delta t$ (17). At the end of the period or sub-period, the metallurgical creep will be $\varepsilon_{0}{ }^{m c}+\Delta \varepsilon^{m c}$. This creep is the initial creep for the following period or sub-period.

$\Delta \varepsilon^{m c}=K \cdot e^{\phi \theta_{\Delta}} \cdot \sigma_{\Delta}{ }^{\beta} \cdot\left[\left(t_{e}+\Delta t\right)^{\mu}-\left(t_{e}\right)^{\mu}\right]$

In order to test both the metallurgic creep and geometrical settlement of core and aluminum, a standard procedure has to be followed [11]-[13].

\section{F. Calculation algorithm}

The calculation algorithm is shown in Fig. 15. The strain summation method algorithm has been adapted so that conductor behavior is analyzed independently from span geometry. The aluminum tension $T_{a}$ is calculated directly as a function of the length of the core $L_{c o r e}$ that is equal to the aluminum length $L_{a}$. Adding core and aluminum tensions, total conductor tension is obtained. From this tension the length due to span geometry $L^{g}$ is calculated and it is compared with conductor length $L^{c}$. Core tension $T_{\text {core }}$ is iterated until the difference is below a threshold value $(0.00001 \%$ of span length).

The process for the calculation of aluminum tension $T_{a}$ is shown in equations (18-20). The first step is the calculation of aluminum total strain $\varepsilon_{\mathrm{a}}$ (18). Then, the strain due to temperature and creep is subtracted and strain due to tension $\varepsilon_{\mathrm{a}}^{\mathrm{T}}$ is obtained (19). The final step is the calculation of aluminum tension $T_{a}(20)$.

$$
\begin{aligned}
& \varepsilon_{a}=\frac{L^{a}}{L_{o}^{a}}-1 \\
& \varepsilon_{a}^{T}=\varepsilon_{a}-\varepsilon_{a}^{\theta}-\varepsilon_{a}^{\text {creep }} \\
& T_{a}=\varepsilon_{a}^{T} \cdot E_{a} \cdot A_{a}
\end{aligned}
$$

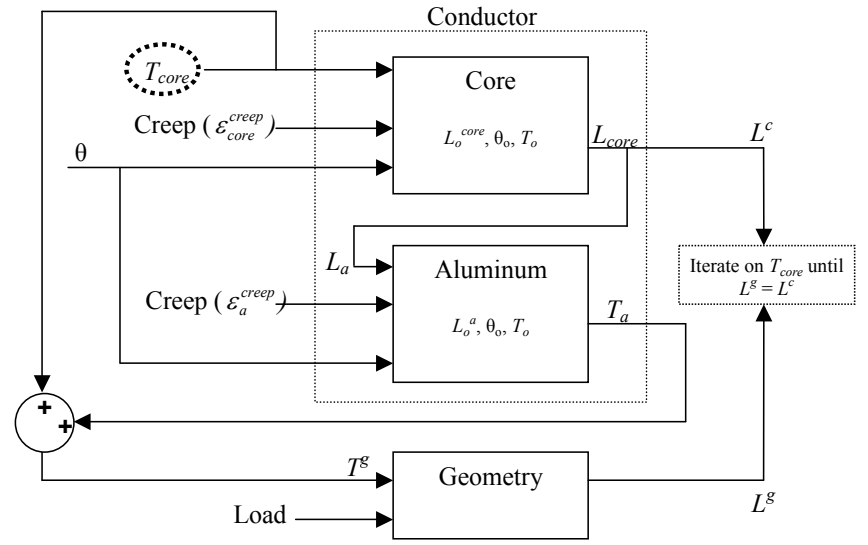

Fig. 15. Iterative process of STOC sag-tension calculation method.

If the aluminum is slack because temperature goes beyond the knee-point temperature, the calculated strain due to tension $\varepsilon_{\mathrm{a}}^{\mathrm{T}}$ will be negative. In this case, the calculated aluminum tension $T_{a}$ also will be negative. However, aluminum tension does not go below its minimum value. This minimum value is zero or a negative value if compression is considered. This is taken into account in the algorithm when aluminum tension $T_{a}$ is evaluated.

\section{G. Application example}

A test has been carried out in order to characterize the temperature behavior of a GTACSR 265 conductor. Conductor data is shown in Table I. Conductor weight is $1.094 \mathrm{~kg} / \mathrm{m}$.

TABLE I

GTACSR 265 CONDUCTOR CHARACTERISTICS

\begin{tabular}{|l|c|c|c|}
\cline { 2 - 4 } \multicolumn{1}{c|}{} & $E(\mathrm{~N} / \mathrm{mm} 2)$ & $A\left(\mathrm{~mm}^{2}\right)$ & $\alpha\left({ }^{\circ} \mathrm{C}^{-1}\right)$ \\
\hline Steel & 205800 & 43.1 & $11.5 \cdot 10^{-6}$ \\
\hline Aluminum & 61740 & 265.3 & $23 \cdot 10^{-6}$ \\
\hline
\end{tabular}

The test span length is $105 \mathrm{~m}$. Conductor temperature has been measured by a thermocouple installed in the center of the span. Sag has been measured by a displacement meter situated below the span. Conductor tension, ambient temperature, solar radiation and wind velocity and direction have been also measured. During the test, the ambient temperature value has been $26{ }^{\circ} \mathrm{C}$, the solar radiation has changed between 500 $\mathrm{W} / \mathrm{m}^{2}$ and $800 \mathrm{~W} / \mathrm{m}^{2}$ and the wind velocity between $0.2 \mathrm{~m} / \mathrm{s}$ and $4.4 \mathrm{~m} / \mathrm{s}$. Conductor temperature has been raised increasing the current value up to $1012 \mathrm{~A}$.

The test has been emulated by STOC and the obtained results have been compared with the measured ones in the test line. The first step in the STOC calculation process is the determination of the strain related to the installation condition and the reference lengths. The conductor has been installed with a tension value of $13161 \mathrm{~N}$ at a temperature of $32.5^{\circ} \mathrm{C}$. The strain related to temperature $\varepsilon^{\theta}$ is obtained taking into account the temperature difference between the installation temperature, $32.5^{\circ} \mathrm{C}$, and the reference temperature, $15^{\circ} \mathrm{C}$. The strain related to tension $\varepsilon^{\mathrm{T}}$ is zero for the aluminum as it is 
slack when the installation is completed. For the steel, the whole conductor tension, $13161 \mathrm{~N}$, is considered. Finally, the strain due to creep $\varepsilon^{\mathrm{c}}$ is calculated. During the installation, the aluminum has been under the $70 \%$ of the installation tension for a few minutes and the steel has been suspended during one hour under the final installation tension so that aluminum gets relaxed. In order to calculate the creep strain, published stressstrain curves of the conductor have been used [14]. These curves represent one hour creep performance of both steel and aluminum. Once the total strain is obtained, the reference lengths can be calculated. The conductor length at the installation condition is $105.03 \mathrm{~m}$. The obtained results are shown in Table II.

Once the reference lengths are known, any condition can be calculated. The temperature conditions of the test have been calculated. In this case, creep strain values are those corresponding to the installation. Measured and calculated values are compared in Fig. 16. A close agreement is achieved between test and STOC results.

TABLE II

STRAINS CORRESPONDING TO THE INSTALLATION CONDITION AND REFERENCE LENGTHS

\begin{tabular}{|l|l|l|l||l||l|}
\cline { 2 - 5 } \multicolumn{1}{c|}{} & $\varepsilon^{\theta}$ & $\varepsilon^{T}$ & $\varepsilon^{\text {creep }}$ & $\varepsilon$ & $L_{o}(\mathrm{~m})$ \\
\hline Steel & 0.0002 & 0.0015 & 0.0001 & 0.0018 & 104.84 \\
\hline Aluminum & 0.0004 & 0 & 0.0007 & 0.0011 & 104.92 \\
\hline
\end{tabular}

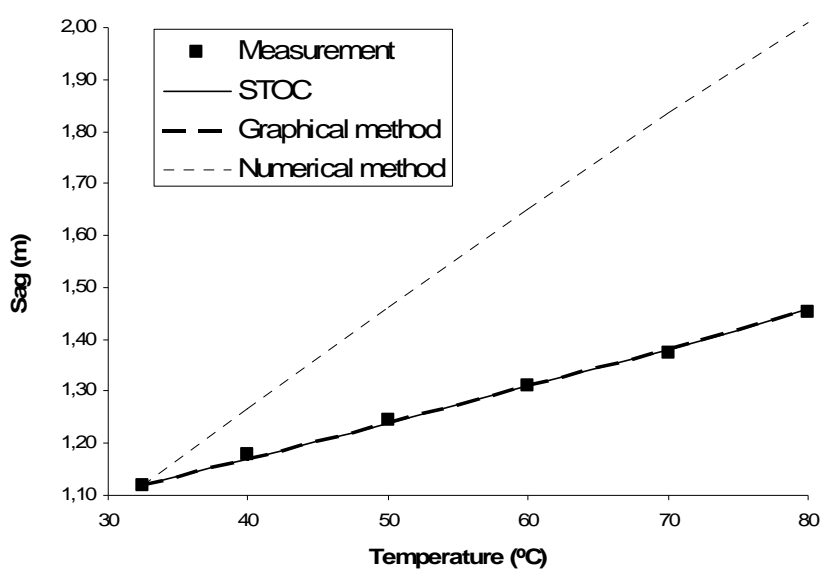

Fig. 16. Comparison between test results and calculation

The calculation has been also carried out using the graphical and numerical methods in order to compare the results obtained from these widely used methods. The reference condition is the initial temperature and the corresponding tension value. The results show that the sag values given by the numerical method that models the conductor as a whole are higher than the measured ones. This is because this method is not able to model the transition process where the aluminum gets slack. In contrast, the graphical method gives identical results as the STOC method. This is because in the example, both the graphical and the STOC method have the same reference value and both make the same linear calculation. In both cases, the aluminum is slack. Creep has not influenced the results of the example as the test has been carried out just after the installation has been completed. The real advantage of the STOC method is achieved when evaluating long term creep as a function of previous creep stages. In this case, there is a difference between the graphical and the STOC methods.

\section{H. STOC versus Graphical method}

As it has been mentioned in the application example, the main difference between the STOC and the graphical method is related to the evaluation of long term creep.

In order to quantify the difference, a case of a line span including long term creep has been calculated. The span length is $350 \mathrm{~m}$ and the conductor is the GTACSR 265. The installation tension is $16111 \mathrm{~N}$ (15\% RTS) and it has been carried out at $15{ }^{\circ} \mathrm{C}$. The initial sag is $10.20 \mathrm{~m}$. The aluminum is slack.

In order to compare the methods, metallurgical creep is evaluated following the graphical method, that is to say, considering 10 years at a constant temperature of $15^{\circ} \mathrm{C}$. The maximum tension conditions evaluated are those established in the Spanish regulation.

As it takes into account the different installation stages and their duration, the creep related to the installation is higher in the STOC method. Hence, the removed metallurgical creep is higher and this decreases the final creep. However, the results show that the effect of removing more steel metallurgical creep is negligible. This is because steel creep is low.

In the maximum tension condition, the aluminum tension is higher if the installation geometrical settlement has been previously removed. Therefore the steel tension is lower, decreasing the related steel geometrical settlement value. In Table III, the tension and sag calculated for the maximum tension condition in Spanish lines above $1000 \mathrm{~m}$ above sea level is shown. This condition considers ice load at $20^{\circ} \mathrm{C}$.

TABLE III

TENSION AND SAG IN THE MAXIMUM TENSION CONDITION

\begin{tabular}{|l|l|l|l||l|}
\cline { 2 - 5 } \multicolumn{1}{c|}{} & $T_{a}(\mathrm{~N})$ & $T_{\text {core }}(\mathrm{N})$ & $T(\mathrm{~N})$ & $D(\mathrm{~m})$ \\
\hline Graphical & 13838 & 23638 & 37475 & 11.25 \\
\hline STOC & 16327 & 22295 & 38622 & 10.91 \\
\hline
\end{tabular}

The results show that the effect of the decrease in the steel geometrical settlement value is low if the aluminum is slack. However, the effect of the creep removed from the aluminum is significant if the aluminum is under tension. This is the case when sag is limited by ice or wind load. For example, the Spanish regulation establishes three conditions that have to be evaluated to determinate the maximum sag value. One condition is related to high temperatures with no wind. The second condition considers wind at $15^{\circ} \mathrm{C}$. The third condition considers ice at $0^{\circ} \mathrm{C}$. When the wind and ice conditions are evaluated, a lower sag is obtained with the STOC method. This is because the aluminum tension is higher due to the removed geometrical settlement. In the calculated case the difference in sag is $37 \mathrm{~cm}$ in the wind condition and $33 \mathrm{~cm}$ in 
the ice condition (Table IV).

TABLE IV

TENSION AND SAg IN THE MAXIMUM SAg CONDITIONS

\begin{tabular}{|l|l|l|l|l||l|}
\cline { 3 - 6 } \multicolumn{2}{c|}{} & $T_{a}(\mathrm{~N})$ & $T_{\text {core }}(\mathrm{N})$ & $T(\mathrm{~N})$ & $D(\mathrm{~m})$ \\
\hline $\begin{array}{l}\text { Wind at } \\
15^{\circ} \mathrm{C}\end{array}$ & Sraphical & 843 & 20129 & 20972 & 11.27 \\
\cline { 2 - 6 } & STOC & 3009 & 18679 & 21687 & 10.90 \\
\hline $\begin{array}{l}\text { Ice at } \\
0{ }^{\circ} \mathrm{C}\end{array}$ & Graphical & 11270 & 24294 & 35564 & 11.85 \\
\cline { 2 - 6 } & STOC & 13632 & 22952 & 36583 & 11.52 \\
\hline
\end{tabular}

Whereas the graphical method analyzes the considered creep stages independently and chooses the worst case, STOC takes into account all of them and evaluates the creep as a function of previous creep stages. Hence, a higher final creep value is expected in the STOC method. The results confirm the expected behavior. The results show that the sag increase considering both metallurgical creep and geometrical settlement is similar or higher than the addition of sag increases obtained considering them independently. Hence, this is an important advantage of the STOC method. However, as steel creep is not high, the absolute difference is not high either. In the analyzed case the difference in sag is $8 \mathrm{~cm}$ (Table V).

TABLE V

FINAL SAG AT $15^{\circ} \mathrm{C}$

\begin{tabular}{|l|l|l|l|}
\cline { 2 - 4 } \multicolumn{1}{c|}{} & $\begin{array}{l}\text { Graphical } \\
\text { Load }\end{array}$ & $\begin{array}{l}\text { Graphical } \\
\text { Creep }\end{array}$ & $\begin{array}{l}\text { STOC } \\
\text { Load+Creep }\end{array}$ \\
\hline$D(\mathrm{~m})$ & 10.27 & 10.25 & 10.35 \\
\hline
\end{tabular}

\section{CONCLUSIONS}

A sag-tension calculation method suitable for gap-type conductors has been developed. The method is based on strain summation and separate consideration of core and aluminum creep. One of the main advantages of the method is the flexibility for the consideration of several creep stages and the ability to take into account the influence of previous creep stages. Another advantage is the versatility, as it can be adapted to any type of conductor. The method has been implemented in a software tool, called STOC.

The STOC method has been compared with the widely used numerical and graphical methods. Numerical method that models the conductor as a whole has a considerable high temperature error because this method is not able to model the transition process where the aluminum gets slack.

In contrast, the results obtained by the graphical method and the STOC method are similar. Only with ice or wind load cases there is an appreciable difference between both methods. And even in this case, it is not an important difference taking into account other uncertainties related to the conductor installation.

Finally, it has to be emphasized that although graphical and STOC method results are similar, STOC method has several advantages that can be useful in many cases. Especially, the main advantage is that it allows a detailed modeling of conductor installation and other situations that can occur during line lifetime due to the ability to take into account the influence of previous creep stages.

\section{REFERENCES}

[1] "Graphic method for sag-tension calculations for ACSR and other conductors", Alcoa, 1926.

[2] R. Thrash, G. Hudson, D. Cooper, G. Sanders, Overhead Conductor Manual. Southwire, 1994.

[3] L. M. Checa, Lineas de transporte de energía. Marcombo, 1988.

[4] A. Alawar, E. J. Bosze, S. R. Nutt, "A hybrid numerical method to calculate sag of composite conductors", Electric Power Systems Research, Vol. 76, No. 5, pp. 389-94, 2006.

[5] I. Zamora, A. J. Mazon, P. Eguia, R. Criado, C. Alonso, J. Iglesias, J. R. Saenz, "High-temperature conductors: a solution in the uprating of overhead transmission lines", IEEE Power Tech Conf., Porto-Portugal, 2001.

[6] K. Yonezawa, K. Kinoshita, "Gap type conductor", IEEE TP \& C Line Design Meeting, Las Vegas-USA, 2005.

[7] J. Orella, R. Cabero, A. J. Mazón, I. Albizu, M. Landeira, J. Laquidain, P. Morentin, I. Belakortu, L. Azpiazu, "A new type of conductor", POWERGRID EUROPE, Madrid-Spain, 2007.

[8] "Sag-tension calculation methods for overhead lines", CIGRÉ B2-12 Brochure (Ref. No. 324), 2007.

[9] J. S. Barrett, S. Dutta, O. Nigol, "A new computer model of ACSR conductors”, IEEE Trans. Power App. Syst., Vol. PAS-102, No. 3, pp. 614-21, 1983

[10] O. Nigol, J. S. Barrett, "Characteristics of ACSR conductors at high temperatures and stresses", IEEE Trans. Power App. Syst, Vol. PAS100, No. 2, pp. 485-93, 1981.

[11] CIGRE WG 22.05, "Permanent elongation of conductors. Predictor equations and evaluation methods", ELECTRA, No. 75, pp. 63-98, 1981.

[12] "A method of stress-strain testing of aluminum conductor and a test for determining the long time tensile creep of aluminum conductors in overhead lines", Electrical Technical Committee of The Aluminum Association, 1999.

[13] IEC 61395, "Overhead electrical conductors - Creep test procedures for stranded conductors", 1998.

[14] Gap type conductor files for PLS-CADD supplied by J-Power Systems. Revised 17/05/2005.

\section{BIOGRAPHIES}

Igor Albizu was born in Zumaia in 1975. He received his Electrical, Electronic and Control Engineering degree from the University of Navarra (Spain) in 1998, his MSc in Elecronic Instrumentations Systems degree from UMIST (UK) in 1999 and his PhD degree from the University of the Basque Country in 2008. He is currently a lecturer in Department of Electrical Engineering (University of the Basque Country). His research activities are concentrated in the area of Transmission Line Thermal Rating.

Angel Javier Mazón (M’03) was born in Bilbao (Spain) in 1965. He received his Electrical Engineering and $\mathrm{PhD}$ degrees from the University of the Basque Country in 1990 and 1994 respectively. During 1992 he worked in Labein Research Laboratories. He is currently a full time Professor in Department of Electrical Engineering (University of the Basque Country). His research activities are concentrated in the area of Electric Power Systems, Transients Simulation, Fault Analysis and Transmission Line Thermal Rating.

Inmaculada Zamora (M'03) was born in Zamora (Spain) in 1965. She received her Electrical Engineering and $\mathrm{PhD}$ degrees from the University of the Basque Country in 1989 and 1993. She is currently a full time Professor and Dean in Department of Electrical Engineering (University of the Basque Country). Her research activities are concentrated in Electric Power Systems, Transients Simulation, Fault Analysis and Transmission Line Thermal Rating. 